\title{
CAPACIDAD DEL ESTADO Y APOYO A LA DEMOCRACIA: RETOS Y OPORTUNIDADES PARA LA COLOMBIA DEL POSTCONFLICTO*
}

Julián Arévalo Bencardinoa

* DOI: https://doi.org/10.18601/01245996.v20n39.07. Agradezco los comentarios y el apoyo de Verónica Akle, Andrea García, Sebastián Guerrero, Mauricio Pérez y Alberto Supelano. Recepción: 13-02-2018, modificación final: 02-05-2018, aceptación: 11-05-2018. Sugerencia de citación: Arévalo, B., J. (2018). Capacidad del Estado y apoyo a la democracia: retos y oportunidades para la Colombia del postconflicto. Revista de Economía Institucional, 20(39), 159-186.

a Doctor en Ciencia Política. Decano de la Facultad de Economía, Universidad Externado de Colombia, Bogotá, [julian.arevalo@uexternado.edu.co]. 


\section{Capacidad del Estado y apoyo a la democracia: retos y oportunidades para la Colombia del postconflicto}

Resumen. En los últimos años, los sistemas políticos han despertado preocupaciones, entre ellas la que algunos autores llaman "recesión democrática". La discusión reciente se centra en la capacidad del Estado para responder a las demandas ciudadanas. Este artículo estudia la relación entre la capacidad del Estado -entendida como su desempeño en asuntos como brindar seguridad, administrar justicia, recaudar impuestos y garantizar derechos- y el apoyo a los principios democráticos y al régimen colombiano. Los resultados indican que una menor valoración de la capacidad del Estado está asociada con un menor apoyo a los principios y al desempeño de la democracia. Estos resultados se discuten en el contexto de los acuerdos de paz entre el gobierno y las Farc, y de sus implicaciones para el postconflicto en Colombia.

Palabras clave: apoyo a la democracia, democratización, capacidad del Estado, construcción de paz; JEL: A12, D74, D78, H79, Z19.

\section{State capacity and support for democracy: Challenges and opportunities for post conflict Colombia}

Abstract. Over the latest years, one of the major concerns with political systems around the world is what some authors have called the "democratic recession". Some recent discussions on these issues focus on the capacity of the state to respond to the demands of its citizens. This paper studies the relationship between state capacity -understood as state performance on areas such as providing security, justice administration, tax collection and guaranteeing rights-, and support for democratic principles and Colombia's regime. The empirical results show that lower levels of assessment of state's capacity are associated to lower levels of support for democratic principles and performance. These results are discussed in the context of the peace agreements between the Colombian government and the FARC guerrillas, as well as the implications posed by this relationship in regards to the challenges and opportunities for post conflict Colombia.

Keywords: Support for democracy, democratization, state capacity, peace building; JEL: A12, D74, D78, H79, Z19.

Capacidade do Estado e apoio à democracia: desafios e oportunidades para a Colômbia do pós-conflito

Resumo. Nos últimos anos, os sistemas políticos têm despertado preocupações, entre elas as que alguns autores chamam "recessão democrática". A discussão recente centraliza-se na capacidade do Estado para responder às demandas cidadãs. Este artigo estuda a relação entre a capacidade do Estado - entendida como seu desempenho em assuntos como proporcionar segurança, administrar justiça, arrecadar impostos e garantir direitos - e o apoio aos princípios democráticos e ao regime colombiano. Os resultados indicam que uma menor valoração da capacidade do Estado está associada com um menor apoio aos princípios e ao desempenho da democracia. Esses resultados são discutidos no contexto dos acordos de paz entre o governo e as Forças Armadas Revolucionárias da Colômbia, e suas consequências para o pós-conflito na Colômbia.

Palavras-chaves: apoio à democracia, democratização, capacidade do Estado, construção de paz.; JEL: A12, D74, D78, H79, Z19. 
$\mathrm{E}$ $n$ la última década una de las principales preocupaciones suscitadas por los sistemas políticos es lo que algunos autores denominan "recesión democrática", es decir, el cese del avance de la democracia y el retroceso con respecto a los avances logrados durante la tercera ola de democratización (Diamond, 2009,2015,2016; Møller y Skaaning, 2013). Desde distintas perspectivas, la democracia ha perdido terreno desde 2006, con casos tan notables como los de Botsuana, Hungría, Nicaragua, Rusia, Tailandia, Turquía y Venezuela, y hay dudas crecientes sobre las posibilidades de transición y consolidación democráticas en los países de la primavera árabe, con la posible excepción de Túnez (Danahar, 2013; Gyimah-B., 2015; Mainwaring y Pérez-L., 2015; Masoud, 2015; Rupnik, 2012; Shevtsova, 2015).

E1 debilitamiento de la democracia en varias partes del mundo coincide con un apoyo creciente a regímenes autoritarios (Micklethwait y Wooldridge, 2014) y la consolidación de distintas formas de autoritarismo competitivo (Levitsky y Way, 2010), acompañados de un cambio de valores y principios que se alejan de los de la democracia liberal (Cooley, 2015).

Parte del escepticismo sobre el desempeño de la democracia se ha explicado por las mayores expectativas de la población asociadas a mejores condiciones de vida en lo económico y lo social (Norris, 2011). Sin embargo, a pesar de la evidencia empírica de este fenómeno en países desarrollados, hay indicios de que los ciudadanos de países menos desarrollados tienen más confianza en sus líderes e instituciones políticas que los del mundo desarrollado (Inglehart y Welzel, 2005).

Otras explicaciones del descontento con la democracia se centran en la incapacidad del Estado para responder a las demandas ciudadanas. Por ejemplo, según Fukuyama (2015) la actual recesión democrática en muchas partes del mundo tiene fuerte relación con una creciente insatisfacción hacia regímenes democráticos que no son capaces de responder a sus ciudadanos en temas como la seguridad o la garantía de otros derechos básicos, así como con situaciones en las que importantes instituciones estatales han sido capturadas por organizaciones criminales.

La discusión sobre el estado de la democracia en el mundo es de especial interés para Colombia después de las negociaciones de paz entre el gobierno y las Farc en La Habana. El acuerdo sobre el punto de participación política propuso una "apertura democrática para la construcción de paz" e introdujo un conjunto de políticas encaminadas a abrir y mejorar la democracia como condición para consolidar la paz (Delegación del Gobierno Nacional y Delegación 
de las Farc-EP, 2013). Así mismo, los acuerdos hicieron hincapié en que la etapa de construcción de paz requería la participación activa de la ciudadanía, en particular de las comunidades de los territorios más afectados por el conflicto.

Además, los acuerdos incluyen disposiciones encaminadas a fortalecer la capacidad del Estado para mejorar las condiciones de seguridad, administrar justicia, garantizar los derechos en zonas rurales y recaudar tributos municipales.

Este artículo estudia la relación entre la capacidad del Estado y el apoyo a los principios y al funcionamiento del régimen democrático en Colombia. Muestra que, si bien los habitantes de países en desarrollo tienen mayores niveles de confianza en sus líderes e instituciones, el fracaso del Estado en cumplirles a sus ciudadanos está ligado a evaluaciones más críticas de los principios y el desempeño de la democracia. Una relación empírica positiva entre capacidad del Estado y apoyo a la democracia sería un reto para la Colombia del postconflicto en la medida en que una insuficiente capacidad podría impedir el cumplimiento de uno de los puntos básicos del acuerdo: la apertura democrática. A la vez, cuando se considera la existencia de una causalidad en dirección contraria, pero también de signo positivo, (es decir, a mayor nivel de democracia mejor es la evaluación del desempeño estatal) la apertura de espacios democráticos para discutir la implementación de los acuerdos, entendida como una innovación democrática, podría llevar a que la gente tenga una mejor valoración de la capacidad del Estado y a que se genere un círculo virtuoso de apertura democrática y fortalecimiento del Estado.

La primera sección sintetiza la teoría del apoyo al régimen, discute el concepto de déficit democrático y revisa la literatura empírica sobre el tema. En la segunda sección se describen algunos aspectos básicos del Estado y la democracia colombianos. En la tercera se hace un análisis empírico de la capacidad del Estado y del apoyo a la democracia en Colombia. En la cuarta se discuten estos resultados desde la perspectiva de los Acuerdos de La Habana. Y en la última se presentan las conclusiones.

\section{APOYO A LA DEMOCRACIA: TEORÍA Y EVIDENCIA}

En sus Consideraciones sobre el gobierno representativo, John Stuart Mill argumentó:

E1 pueblo al que se destina una forma de gobierno debe tener la voluntad de aceptarlo; o al menos no tan poca voluntad que oponga obs- 
táculos insuperables a su establecimiento. Debe tener la voluntad y ser capaz de hacer lo que sea necesario para mantenerlo en funcionamiento. (Mill, 1862)

Esta afirmación es particularmente importante para las democracias, pues la "voluntad del pueblo" es lo que les da su legitimidad y su existencia continua. Con la tercera ola de democratización que comenzó a mediados de la década de 1970, y su recesión desde mediados de la década de 2000, una agenda de investigación ha sido estudiar las variables que afectan el apoyo a los regímenes democráticos y las condiciones que socavan el apoyo de la población a la democracia.

Según Easton (1965) el apoyo a los sistemas políticos se puede estudiar en tres dimensiones: al Estado-nación, a sus agencias y a sus actores. El apoyo al Estado-nación refleja una idea abstracta que incluye sentimientos como la pertenencia a una comunidad nacional, el orgullo nacional, el patriotismo y la identidad. Es algo difuso y no puede identificarse con unos pocos individuos, agencias o políticas. El apoyo a agencias y a actores, por el contrario, es mucho más concreto pues se refiere al desempeño de instituciones del régimen y de actores específicos que detentan posiciones de poder en un momento dado. Este es el caso del presidente, las cortes, la policía y los militares, así como de los representantes elegidos, los líderes de partidos y los partidos políticos. Desde esta perspectiva, cabría esperar que, dado el carácter abstracto del apoyo al sistema, sea más estable y duradero que el apoyo a agencias y a actores (Norris, 2011).

Norris extiende el carácter multidimensional del sistema de apoyo de Easton y propone cinco categorías de estudio: 1) apoyo a la comunidad, 2) principios y valores del régimen, 3) desempeño del régimen, 4) instituciones del régimen y 5) actores políticos. Así como en la versión simplificada, estas dimensiones forman un continuum que va del apoyo abstracto y difuso al Estado-nación al apoyo más específico a políticos y funcionarios.

E1 apoyo a los principios y valores capta la adhesión a ideas que forman el núcleo del régimen. Por ejemplo, en un sistema democrático algunos de sus principios y valores son la libre y equitativa elección a cargos públicos y el respeto de derechos y libertades fundamentales. Ahora bien, mientras que la evaluación del desempeño del régimen se relaciona con su funcionamiento, la confianza en sus instituciones atañe a la aprobación pública de quienes detentan el poder. Así, la confianza en las instituciones capta cómo se manejan distintos ámbitos de política: economía, seguridad, administración de justicia y política social. La parte empírica de este artículo investiga en qué medida las 
variables de democracia dependen de las variables de capacidad del Estado.

La ampliación de la categoría intermedia permite que Norris (2011) explique el déficit democrático: la brecha entre lo que el pueblo espera recibir de la democracia (principios y valores del régimen) y la satisfacción con su desempeño real (desempeño del régimen). Este déficit se observa hoy en muchas sociedades: el sentimiento de personas que aspiran a la democracia y consideran que es la forma ideal de gobierno, al tiempo que son escépticas ante el desempeño de la democracia en su propia sociedad.

La investigación sobre la modernización y la teoría del postmaterialismo ofrecen una posible explicación del déficit democrático. Según esta teoría, la etapa postmoderna de desarrollo en sociedades industriales avanzadas ha provocado un cambio de valores, que hace más críticos a los ciudadanos y más escépticos ante todo tipo de autoridad. Pero, pese a la pérdida de respeto por la autoridad (que se traduce en menor apoyo a gobiernos, partidos políticos jerárquicos y formas de participación dirigidas por élites) el apoyo a los principios democráticos ha crecido (Inglehart, 1999; Inglehart y Welzel, 2010). Esto implica que, aun controlando por percepciones de desempeño estatal, un mayor nivel de desarrollo socio-económico aumenta las expectativas acerca de la democracia y crea una brecha democrática cuando esta no cumple las expectativas de los ciudadanos.

Si bien esta teoría tiene respaldo empírico en sociedades desarrolladas, no es necesariamente válida para naciones en desarrollo. En las sociedades menos desarrolladas, la gente tiene más confianza en sus líderes e instituciones políticas que en el mundo desarrollado (Inglehart y Welzel, 2005). En otros términos, la teoría de la modernización y el post materialismo ayudan a explicar el descontento con el funcionamiento de la democracia en sociedades avanzadas, pero no en países menos desarrollados. Este enfoque, basado en expectativas y actitudes ciudadanas, puede entenderse como una explicación "desde la demanda”.

Como complemento, las explicaciones "desde la oferta" se basan en el incumplimiento de los gobiernos con sus sociedades. Norris (2011) identifica tres dimensiones de desempeño del régimen como posibles fuentes de variabilidad en el lado de la oferta de la ecuación del déficit democrático: 1) desempeño de proceso, 2) desempeño de políticas y 3) estructuras institucionales. El desempeño de proceso se refiere a la calidad intrínseca de la gobernanza democrática: incluye la valoración de la limpieza de las elecciones, la responsabilidad y rendición 
de cuentas de los representantes elegidos, y medidas de transparencia y corrupción. El desempeño de políticas incluye la evaluación de la provisión de servicios públicos, atención en salud, seguridad ciudadana y otras condiciones de vida. Finalmente, las estructuras institucionales subrayan la importancia de los arreglos constitucionales, en especial de las estructuras de reparto del poder. Este enfoque permite evaluar regímenes con base en el juicio informado de los ciudadanos acerca de un gobierno o una serie de gobiernos.

Estudios recientes sobre el estado de la democracia emplean indicadores de desempeño de políticas como principales variables explicativas. Entre ellas, el desempeño económico juega un papel principal. Por ejemplo, Kotzian (2011) encuentra que el apoyo a la democracia depende de la estabilidad económica y esto lo lleva a argumentar que esta variable tiene mayor valor explicativo que el desarrollo político e institucional. Por su parte, Krieckhaus et al. (2014) encuentran que una mayor desigualdad económica reduce el apoyo a la democracia. Armingeon y Guthmann (2014) sostienen que las políticas adoptadas en economías europeas en el contexto de la gran recesión que comenzó en 2008 se tradujeron en menor apoyo a la democracia. Rudra (2005) argumenta que una mayor apertura a los mercados internacionales lleva a un mayor apoyo a la democracia, si va acompañada de un fortalecimiento del Estado de bienestar. La evidencia indica entonces que el apoyo a la democracia depende mucho de la política y el desempeño económicos.

Además de la dimensión económica, la investigación sobre el desempeño de políticas también aborda el papel de las instituciones estatales. Haerpfer (2008) estudia el caso de Rusia de 1992 a 2002, combinando variables económicas y políticas, y argumenta que el predictor más importante de apoyo al régimen es la situación macroeconómica y que la confianza en las instituciones del gobierno es el segundo predictor más importante. Magalhães (2014) sostiene que la calidad de la formulación y la implementación afecta las preferencias sobre regímenes, mientras que Andersen et al. (2014) encuentran que la capacidad del Estado mejora la estabilidad del régimen ${ }^{1}$.

Usando datos de países de América Latina y África, Fernández y Kuenzi (2010) encuentran que las percepciones ciudadanas de seguridad tienen efectos significativos en el apoyo a la democracia y

${ }^{1}$ También sostiene que, en esta relación, las dimensiones de capacidad del Estado son distintas en autocracias y democracias. Para la estabilidad de las autocracias lo más importante es el monopolio de la violencia; para la estabilidad de las democracias, el factor clave es la efectividad administrativa. 
en la satisfacción con la democracia. En Ghana y Zambia, Bratton y Mattes (2001) encuentran que aun en presencia de apoyo intrínseco a la democracia, el nivel general de apoyo a la misma depende mucho del desempeño de los gobiernos.

Este artículo presenta evidencia en favor de la hipótesis de que, en el caso colombiano, el desempeño de políticas -en especial en materia de seguridad, administración de justicia, recaudo de impuestos y garantía de derechos- tiene una fuerte relación con el apoyo a los principios y el desempeño de la democracia. Antes de ello, la siguiente sección hace una breve descripción de la situación de la capacidad estatal y de la democracia en el país.

\section{CAPACIDAD ESTATAL Y DEMOCRACIA EN COLOMBIA}

En las últimas décadas, el Estado colombiano ha ejercido un creciente control del territorio, con la consiguiente regresión de grupos armados que aspiraban a dominarlo a finales del siglo anterior. Al mismo tiempo ha mejorado la capacidad regulatoria de las instituciones en administración de la justicia y protección de derechos de propiedad (Duncan, 2014), lo que implica la reversión de la tendencia al “colapso de la autoridad" (Centeno, 2002) que mencionaban algunos autores al referirse a Colombia. Sin embargo, el país aún enfrenta retos importantes para consolidar un Estado moderno y democrático.

Uno de los principales problemas que hoy enfrenta el Estado es el de las mafias y otras organizaciones que extraen recursos de actividades ilegales y amenazan la seguridad de los ciudadanos. Hasta hace poco, en muchas regiones había presencia activa de las Farc, mientras que el Ejército de Liberación Nacional (ELN) y las agrupaciones que aparecieron después de la desmovilización de los paramilitares, a mediados de la década de 2000, realizan actividades orientadas al control territorial (Patiño, 2012). Algunas -las bandas criminales o Bacrim- que actúan en zonas urbanas y se dedican a la extorsión, el narcotráfico y el contrabando, generan dramáticas condiciones de inseguridad en ciudades como Medellín, Barranquilla, Cúcuta y Cali, y son una gran amenaza para activistas de derechos humanos y líderes sociales (CNMH, 2013).

E1 Estado colombiano también tiene dificultades para garantizar los derechos de propiedad, particularmente en zonas rurales, con frecuencia asociadas a la corrupción o incapacidad de las agencias encargadas de administrar la información sobre esos derechos (Gómez, 2009). Las deficiencias en la especificación de los derechos de propie- 
dad sobre la tierra contribuyen a explicar los altos niveles de violencia y represión política que han caracterizado al país (Gutiérrez, 2014).

Además de los problemas de seguridad, otra dimensión pertinente es la administración de justicia. Según García (2008), el Estado enfrenta importantes obstáculos para administrar justicia en todo el territorio. Algunos están asociados al manejo de la seguridad, la “captura" del sistema judicial por intereses económicos y políticos locales y la intimidación de jueces y otros funcionarios de la rama judicial por grupos armados ilegales. En general, la ciudadanía tiene un mal concepto del sistema judicial. Por ejemplo, en la base de datos que utiliza este artículo solo el $31,2 \%$ de los encuestados están satisfechos o muy satisfechos con el funcionamiento del sistema judicial. Sin embargo, la situación de la administración de justicia no es uniforme en todo el territorio; es muy heterogénea y especialmente crítica en regiones con presencia significativa de grupos armados ilegales y cuyas economías no se han integrado a la dinámica del resto del país.

Una tercera dimensión de la capacidad estatal es el recaudo de impuestos; pero esta requiere diferenciar dos niveles de institucionalidad. A nivel nacional, el gobierno ha mejorado visiblemente la capacidad de recaudo; pero, en el nivel local, muchos municipios muestran debilidad fiscal, principalmente en el recaudo del impuesto predial (Kalmanovitz, 2010).

La cuarta dimensión atañe a la capacidad del Estado para garantizar los derechos económicos y sociales y proveer servicios y bienes públicos. La Constitución política responsabiliza al Estado de garantizar el acceso a servicios de salud, educación y vivienda. Sin embargo, en esta, como en otras dimensiones, su desempeño es insuficiente y caracterizado por desigualdades regionales (DNP, 2011a y 2011b; PNUD, 2011).

En términos integrales, el resultado es lo que algunos estudiosos llaman "presencia diferenciada del Estado" en el territorio (González, Bolívar y Vásquez, 2002; González, 2014), porque el alcance y el desempeño de las instituciones estatales en el territorio son muy heterogéneos. Esto crea brechas en la manera de garantizar los derechos económicos, sociales y políticos, y abre espacio para que actores ilegales coopten y reconfiguren esas instituciones. Esta situación impide consolidar un Estado Social de Derecho (Garay y Salcedo-A., 2012).

$\mathrm{E} 1$ estado de la democracia también tiene graves problemas. El sistema electoral se caracteriza por el clientelismo, la falta de transparencia en la financiación de campañas políticas, la poca confianza 
en las instituciones políticas y la presencia de intereses ilegales en la política (De la Calle, 2008).

Al mismo tiempo, la participación ciudadana en espacios democráticos no electorales es muy baja; esto se asocia en parte a la presencia de conflicto armado y al contexto de clientelismo y corrupción (Alviar, Azuero y Bejarano, 2009; Velásquez y González, 2003). Desde los años noventa, los intentos de institucionalizar mecanismos de participación se asociaron a frenos a la movilización social (Velásquez, 2015), y sigue siendo un reto mayúsculo alcanzar un mayor nivel de participación ciudadana.

Regresando al concepto de "déficit democrático", el caso de Colombia es un buen ejemplo de la brecha entre lo que la población espera de la democracia y su nivel de satisfacción con lo que le entrega en la práctica. Los datos de las rondas 2011, 2013 y 2015 de Latinbarómetro permiten cotejar el porcentaje de personas que responde cuán satisfecho está con el funcionamiento de la democracia en Colombia con el de quienes piensan que es el mejor sistema. La gráfica 1 indica que si bien el $18 \%$ de los encuestados está muy de acuerdo con la afirmación de que la democracia es el mejor sistema, solo el 4\% lo está con su funcionamiento. E1 61\% considera que la democracia es el mejor sistema, pero solo el $24 \%$ está más bien satisfecho con la forma como funciona en el país.

Gráfica 1

Déficit democrático en Colombia

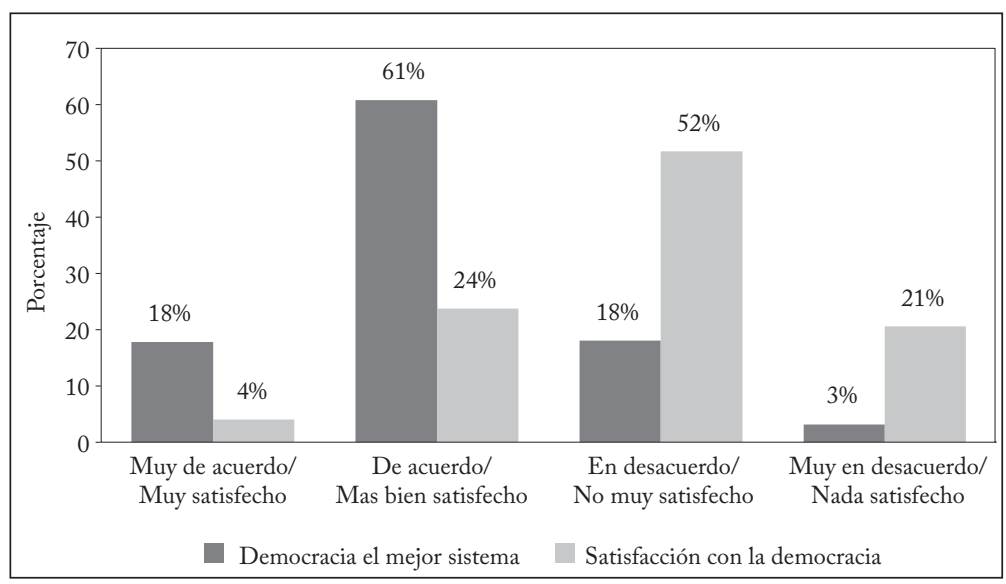

Fuente: Latinbarómetro 2011, 2013, 2015.

En suma, la gráfica 1 indica que hay descontento con la democracia, pese a las expectativas que genera en la ciudadanía. La siguiente 
sección presenta evidencia empírica que apoya la hipótesis de que los bajos niveles de satisfacción con la democracia colombiana están asociados a una insuficiente capacidad estatal para cumplir las expectativas de la población en materia de seguridad, administración de justicia, recaudo tributario y garantía de derechos. Las tasas de aprobación de la democracia como el mejor sistema de gobierno también están asociadas a estas dimensiones de la capacidad estatal.

\section{ANÁLISIS EMPÍRICO}

Esta sección analiza la relación empírica entre los principios del régimen y su desempeño en materia de procesos (categorías 2 y 3 del esquema de Norris) y el desempeño del régimen en materia de políticas y sus instituciones (categorías 3 y 4). Como línea de base se usa la ronda 2011 de Latinbarómetro, y cuando la información está disponible se complementa con las rondas 2013 y 2015. Cada conjunto de datos incluye 1.200 observaciones individuales.

El lado izquierdo de la ecuación de regresión estudia tres variables asociadas a distintas dimensiones de apoyo al régimen. La primera medida capta el apoyo a los principios del régimen, usando la variable democracia como mejor sistema, y tomando como base la siguiente afirmación: "La democracia puede tener problemas, pero es el mejor sistema de gobierno". Las respuestas a esta pregunta se codifican en una escala de 4 puntos, que van de "muy de acuerdo", 4, a "muy en desacuerdo", 1 .

Para captar información sobre el desempeño del régimen, se usaron dos medidas adicionales de apoyo a la democracia. Se preguntó: "En general, ¿diría que está muy satisfecho, más bien satisfecho, no muy satisfecho o nada satisfecho con el funcionamiento de la democracia en Colombia?" A partir de esta pregunta se construyó la variable satisfacción con la democracia, que tiene valores mayores para mayores niveles de satisfacción con la democracia. Y la variable la democracia ha mejorado se construyó a partir de la respuesta a la siguiente pregunta: “C Cree que la democracia en Colombia ha mejorado, se ha mantenido igual [o ha] empeorado?” Las estadísticas descriptivas, las definiciones y la codificación de estas y otras variables se encuentran en el anexo.

En el lado derecho de las ecuaciones se estudiaron cuatro dimensiones de capacidad estatal: provisión de seguridad, administración de justicia, recaudo tributario y garantía de derechos. Para permitir distintas aproximaciones a estos temas, cada dimensión incluye dos o más variables, que se explican a continuación. En la dimensión 
de provisión de seguridad se incluyeron cinco variables: protección contra el crimen, ha sido asaltado, evalúe la seguridad pública, teme ser víctima y protección de la propiedad privada. En la dimensión administración de justicia se incluyeron: se benefició de la política judicial y está satisfecho con el sistema judicial. En recaudo tributario, las dos variables pertinentes fueron: cuánta gente paga impuestos y confianza en el uso del recaudo. Y en garantía de derechos se eligieron cuatro variables: se benefició de la política educativa, se benefició de la política de salud, se benefició de la política de vivienda y qué ha hecho el Estado por usted.

Para tener en cuenta la teoría de la modernización y otras explicaciones posibles, usamos como variables de control la edad, el género, el nivel de ingreso, la educación, la ideología y la religiosidad de los encuestados.

Se estimaron varios modelos con regresiones logit ordinales para cada variable dependiente. Cada regresión solo tiene una variable independiente y las variables de control en el lado derecho, además de dummies de año cuando había información para más de un año; por ejemplo, la primera regresión democracia como mejor sistema con respecto a protección contra el crimen, más las variables de control y dummies anuales para 2013 y 2015.

Puesto que la mayoría de las variables independientes son ordinales se crearon variables dummy para cada una de ellas usando el valor más bajo como categoría excluida. Los coeficientes que figuran en el cuadro 1 son los de cada regresión, que incluye una variable independiente y las dummies de control de año, de modo que no hay problemas de multicolinealidad.

Todas las regresiones incluyen mínimo 856 observaciones y máximo 2819 (dependiendo del número de años incluidos), y todos los resultados incluyen errores heteroscedásticos estándar robustos. Los resultados se presentan en el cuadro 1 y los efectos marginales en la gráfica 2 .

Antes de iniciar el análisis de las variables independientes de interés, cabe mencionar que se encontró una relación estadísticamente significativa para las variables ingreso e ideología en todas las regresiones (no reportadas en el cuadro). Es decir, las personas de mayores ingresos y más a la derecha del espectro político tienden a estar más satisfechas con los valores y el desempeño de la democracia. La educación resultó estadísticamente significativa en las regresiones de democracia como mejor sistema y satisfacción con la democracia (los más educados valoran más la democracia) y la religiosidad solo fue 


\section{Cuadro 1}

Resultados de las regresiones

\begin{tabular}{|c|c|c|c|}
\hline Variable & $\begin{array}{c}\text { Democracia } \\
\text { como mejor } \\
\text { sistema }\end{array}$ & $\begin{array}{c}\text { Satisfacción } \\
\text { con la } \\
\text { democracia }\end{array}$ & $\begin{array}{l}\text { Democracia ha } \\
\text { mejorado }\end{array}$ \\
\hline Protección contra el crimen $(=2)$ & $\begin{array}{l}0,2259^{*} \\
{[0,115]}\end{array}$ & $\begin{array}{c}0,3487^{* * * *} \\
{[0,108]}\end{array}$ & $\begin{array}{c}0,5003^{\text {**** }} \\
{[0,160]}\end{array}$ \\
\hline Protección contra el crimen $(=3)$ & $\begin{array}{l}0,1950 \\
{[0,128]}\end{array}$ & $\begin{array}{l}0,4877^{* * * * *} \\
{[0,124]}\end{array}$ & $\begin{array}{l}0,6692^{* * * *} \\
{[0,173]}\end{array}$ \\
\hline Protección contra el crimen $(=4)$ & $\begin{array}{l}0,4056^{* *} \\
{[0,203]}\end{array}$ & $\begin{array}{l}0,6522^{* * * *} \\
{[0,216]}\end{array}$ & $\begin{array}{r}0,4008 \\
{[0,288]} \\
\end{array}$ \\
\hline Evalúe la seguridad pública (=2) & $\begin{array}{l}0,0160 \\
{[0,190]}\end{array}$ & $\begin{array}{l}0,3626^{* * *} \\
{[0,152]}\end{array}$ & $\begin{array}{l}-0,0895 \\
{[0,371]}\end{array}$ \\
\hline Evalúe la seguridad pública $(=3)$ & $\begin{array}{l}0,2364 \\
{[0,177]}\end{array}$ & $\begin{array}{c}0,8969^{* * * *} \\
{[0,135]}\end{array}$ & $\begin{array}{l}0,6744^{* *} \\
{[0,329]}\end{array}$ \\
\hline Evalúe la seguridad pública $(=4)$ & $\begin{array}{l}0,5372 * \cdots * * \\
{[0,192]}\end{array}$ & $\begin{array}{l}1,5944^{* * * *} \\
{[0,155]}\end{array}$ & $\begin{array}{l}0,9895^{* * * *} \\
{[0,351]}\end{array}$ \\
\hline *Evalúe la seguridad pública (=5) & $\begin{array}{l}0,2097 \\
{[0,305]} \\
\end{array}$ & $\begin{array}{c}2,0791^{* * * * *} \\
{[0,285]}\end{array}$ & $\begin{array}{l}0,9182^{*} \\
{[0,517]}\end{array}$ \\
\hline Protección de la propiedad privada $(=2)$ & $\begin{array}{l}-0,0154 \\
{[0,182]}\end{array}$ & $\begin{array}{l}0,4267^{* * * *} \\
{[0,159]}\end{array}$ & $\begin{array}{l}0,3046 \\
{[0,302]}\end{array}$ \\
\hline Protección de la propiedad privada (=3) & $\begin{array}{l}0,1309 \\
{[0,179]}\end{array}$ & $\begin{array}{c}0,7052^{* * * * *} \\
{[0,158]}\end{array}$ & $\begin{array}{l}0,5851^{\text {*** }} \\
{[0,297]}\end{array}$ \\
\hline Protección de la propiedad privada (=4) & $\begin{array}{c}0,4752^{* *} \\
{[0,194]}\end{array}$ & $\begin{array}{c}1,1683^{* * * *} \\
{[0,178]}\end{array}$ & $\begin{array}{l}0,5932^{*} \\
{[0,313]}\end{array}$ \\
\hline Ha sido asaltado & $\begin{array}{l}-0,0908 \\
{[0,083]}\end{array}$ & $\begin{array}{c}-0,3743^{* * * * *} \\
{[0,079]}\end{array}$ & $\begin{array}{l}-0,1988 \\
{[0,145]}\end{array}$ \\
\hline Teme ser víctima $(=2)$ & $\begin{array}{c}0,1363 \\
{[0,145]}\end{array}$ & $\begin{array}{c}-0,1919 \\
{[0,147]}\end{array}$ & $\begin{array}{c}0,0852 \\
{[0,257]}\end{array}$ \\
\hline Teme ser víctima $(=3)$ & $\begin{array}{l}0,1466 \\
{[0,136]}\end{array}$ & $\begin{array}{c}-0,1462 \\
{[0,131]}\end{array}$ & $\begin{array}{l}0,1423 \\
{[0,230]}\end{array}$ \\
\hline Teme ser víctima $(=4)$ & $\begin{array}{l}0,0796 \\
{[0,137]}\end{array}$ & $\begin{array}{c}-0,5259^{* * * *} \\
{[0,132]}\end{array}$ & $\begin{array}{r}-0,1567 \\
{[0,238]}\end{array}$ \\
\hline Satisfecho con el sistema judicial (=2) & $\begin{array}{c}0,1240 \\
{[0,134]}\end{array}$ & $\begin{array}{c}0,5184^{* * * * *} \\
{[0,123]}\end{array}$ & $\begin{array}{c}0,2640 \\
{[0,183]}\end{array}$ \\
\hline Satisfecho con el sistema judicial (=3) & $\begin{array}{c}0,6102^{* * * *} \\
{[0,147]}\end{array}$ & $\begin{array}{c}1,0518^{* * * * *} \\
{[0,142]}\end{array}$ & $\begin{array}{c}0,5675^{* * * *} \\
{[0,202]}\end{array}$ \\
\hline Satisfecho con el sistema judicial (=4) & $\begin{array}{c}0,3613 \\
{[0,257]}\end{array}$ & $\begin{array}{c}0,9865^{* * * *} \\
{[0,274]}\end{array}$ & $\begin{array}{c}0,7817^{* * * * *} \\
{[0,284]}\end{array}$ \\
\hline Se benefició de la política judicial & $\begin{array}{l}0,5600^{*} \\
{[0,323]}\end{array}$ & $\begin{array}{c}0,1518 \\
{[0,318]} \\
\end{array}$ & $\begin{array}{l}0,5646^{*} \\
{[0,308]}\end{array}$ \\
\hline Confianza en el uso de los recaudos & $\begin{array}{c}0,2726 \\
{[0,216]}\end{array}$ & $\begin{array}{c}0,7849^{\text {****** }} \\
{[0,212]}\end{array}$ & $\begin{array}{c}0,6220^{* * * * *} \\
{[0,192]}\end{array}$ \\
\hline Cuánta gente paga impuestos & $\begin{array}{c}0,0041 \\
{[0,003]}\end{array}$ & $\begin{array}{c}0,0032 \\
{[0,003]}\end{array}$ & $\begin{array}{l}0,0061^{* *} \\
{[0,003]}\end{array}$ \\
\hline Se benefició de la política de salud & $\begin{array}{c}0,1432 \\
{[0,149]}\end{array}$ & $\begin{array}{l}0,2594^{*} \\
{[0,136]}\end{array}$ & $\begin{array}{c}0,1182 \\
{[0,134]}\end{array}$ \\
\hline Se benefició de la política educativa & $\begin{array}{l}0,2707^{*} \\
{[0,150]}\end{array}$ & $\begin{array}{l}-0,0064 \\
{[0,138]}\end{array}$ & $\begin{array}{l}-0,0204 \\
{[0,130]}\end{array}$ \\
\hline Se benefició de la política de vivienda & $\begin{array}{l}-0,0674 \\
{[0,187]}\end{array}$ & $\begin{array}{l}0,1330 \\
{[0,179]}\end{array}$ & $\begin{array}{l}0,2222 \\
{[0,175]}\end{array}$ \\
\hline Lo que ha hecho el Estado por usted $(=2)$ & $\begin{array}{c}0,1591 \\
{[0,196]}\end{array}$ & $\begin{array}{c}0,4904^{* * * * *} \\
{[0,174]}\end{array}$ & $\begin{array}{c}0,2815 \\
{[0,171]}\end{array}$ \\
\hline Lo que ha hecho el Estado por usted $(=3)$ & $\begin{array}{l}0,3558^{*} \\
{[0,193]}\end{array}$ & $\begin{array}{c}0,8687^{* * * * *} \\
{[0,179]}\end{array}$ & $\begin{array}{c}0,8071^{* * * *} \\
{[0,171]}\end{array}$ \\
\hline Lo que ha hecho el Estado por usted $(=4)$ & $\begin{array}{l}0,5063^{*} \\
{[0,262]}\end{array}$ & $\begin{array}{c}1,2610^{* * * * *} \\
{[0,251]}\end{array}$ & $\begin{array}{c}1,1267^{* * * *} \\
{[0,273]}\end{array}$ \\
\hline Controles & $\mathrm{Si}$ & $\mathrm{Si}$ & $\mathrm{Si}$ \\
\hline
\end{tabular}

Notas: ${ }^{*} \mathrm{p}<0,10 ;{ }^{* *} \mathrm{p}<0,05 ;{ }^{* * *} \mathrm{p}<0,01 ;$ prueba de dos colas. Cada coeficiente de las regresiones logit ordinales es resultado de una regresión entre la variable dependiente y la variable independiente correspondiente (solo una para cada regresión) más variables de control y dummies anuales cuando fue posible. Errores robustos de heteroscedasticidad entre paréntesis cuadrados. 
significativa en la regresión de democracia como mejor sistema (los más religiosos tienen mejor concepto de la democracia).

Pasando a las variables de capacidad estatal, cada gráfica de las que componen las gráficas 2a-2c ilustra los efectos marginales, es decir, indica la probabilidad de que se dé la respuesta más alta posible a la pregunta sobre democracia para todo valor posible de la variable independiente en cada caso. Por ejemplo, la primera gráfica de la gráfica 2a muestra la probabilidad de que la persona encuestada diga que está muy de acuerdo con la afirmación de que la democracia es el mejor sistema de gobierno, para toda posible respuesta a la pregunta de si se siente protegida contra el crimen, dejando todo lo demás constante en su medio respectivo. Como puede observarse, la mayoría de los resultados son monotónicos en la dirección esperada, aunque los resultados no sean siempre estadísticamente significativos.

Para la variable dependiente democracia como mejor sistema, los resultados muestran una relación positiva y estadísticamente significativa solo para dos de las variables de provisión de seguridad; para protección contra el crimen y protección de la propiedad privada. Para evalúe la seguridad pública, la tendencia cambia en el último valor, aunque la probabilidad de estar de acuerdo con la afirmación sobre la democracia sigue siendo mayor que en los niveles más bajos de evaluación de la política. No se encontró una relación estadísticamente significativa con teme ser victima ni con ha sido asaltado. En administración de justicia se encontró una relación positiva y significativa con está satisfecho con el sistema judicial; y con se benefició de la política judicial la relación es positiva pero no significativa estadísticamente. En recaudo tributario no se observó una relación estadísticamente significativa con ninguna de las dos variables. Por último, en garantía de derechos se encontró una relación positiva y estadísticamente significativa con se benefició de la politica educativa (al 90\%) y con lo que ha hecho el Estado por usted, pero no con se benefició de la politica de salud y se benefició de la politica de vivienda.

Para la variable dependiente satisfacción con la democracia, los resultados muestran una relación estadísticamente significativa y del signo esperado con todas las variables de provisión de seguridad: positiva con protección contra el crimen y evalúe la seguridad pública y protección de la propiedad privada, y negativa con ha sido asaltado $\mathrm{y}$ teme ser victima. Con respecto a la justicia, se encontró una relación positiva y significativa con está satisfecho con el sistema judicial. La relación con se benefició de la politica judicial es positiva sin ser significativa. Para las variables de recaudo tributario hay una rela- 
Gráfica 2a

¿Es la democracia el mejor sistema de gobierno?

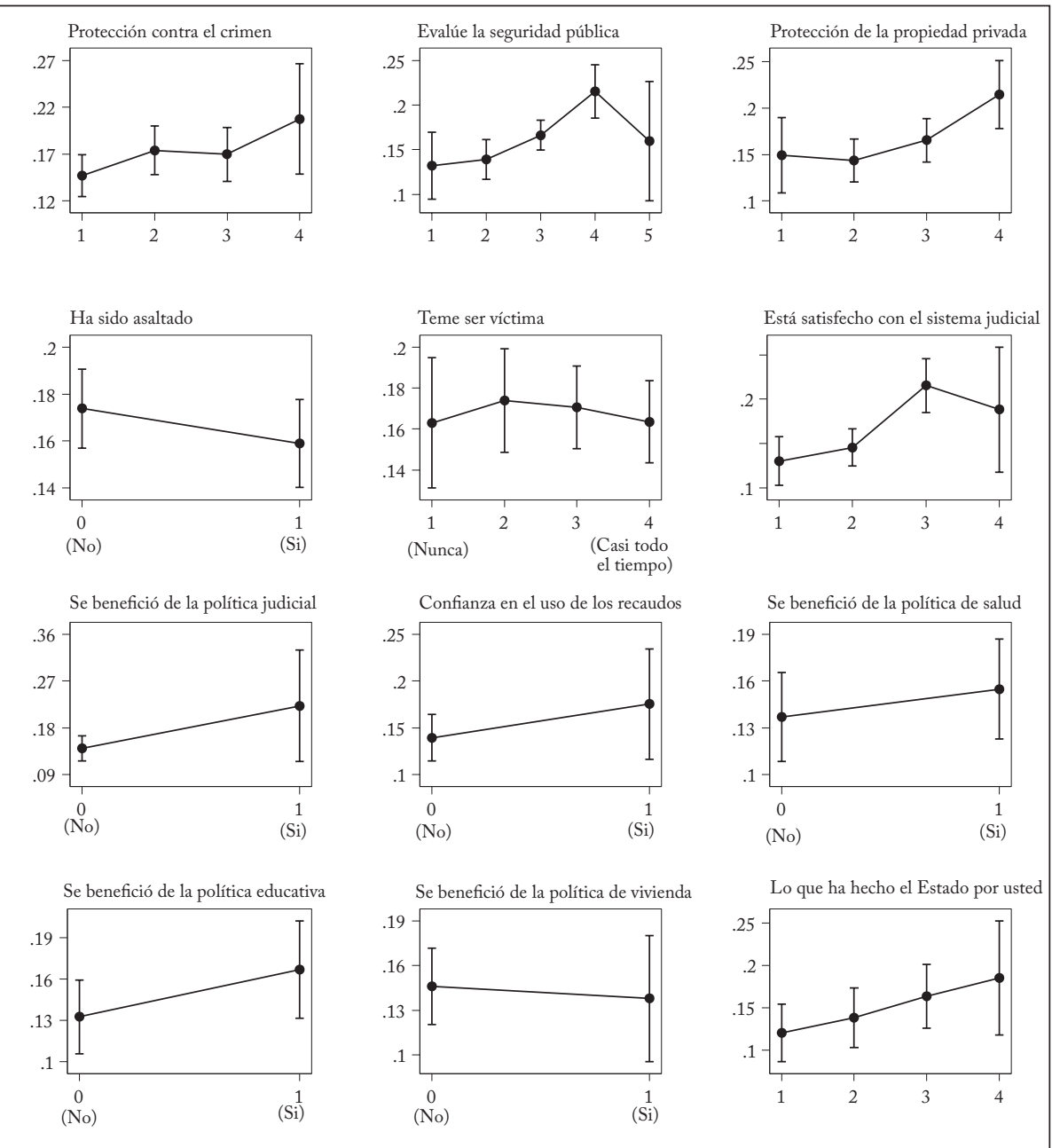

* Si en el anexo no se especifica lo contrario, un mayor valor en el eje x corresponden a una mayor valoración. Nivel de confianza $=95 \%$.

ción positiva y significativa con confianza en el uso de los recaudos, y ninguna con cuánta gente paga impuestos. Además, se encontró una relación positiva y significativa con se benefició de la politica de salud, pero no la hay con se benefició de la politica educativa ni se benefició de la politica de vivienda.

Finalmente, la variable dependiente la democracia ha mejorado muestra una relación positiva y estadísticamente significativa con la mayoría de las variables de provisión de seguridad; una relación 
Gráfica 2b

¿Está satisfecho con el funcionamiento de la democracia en Colombia?
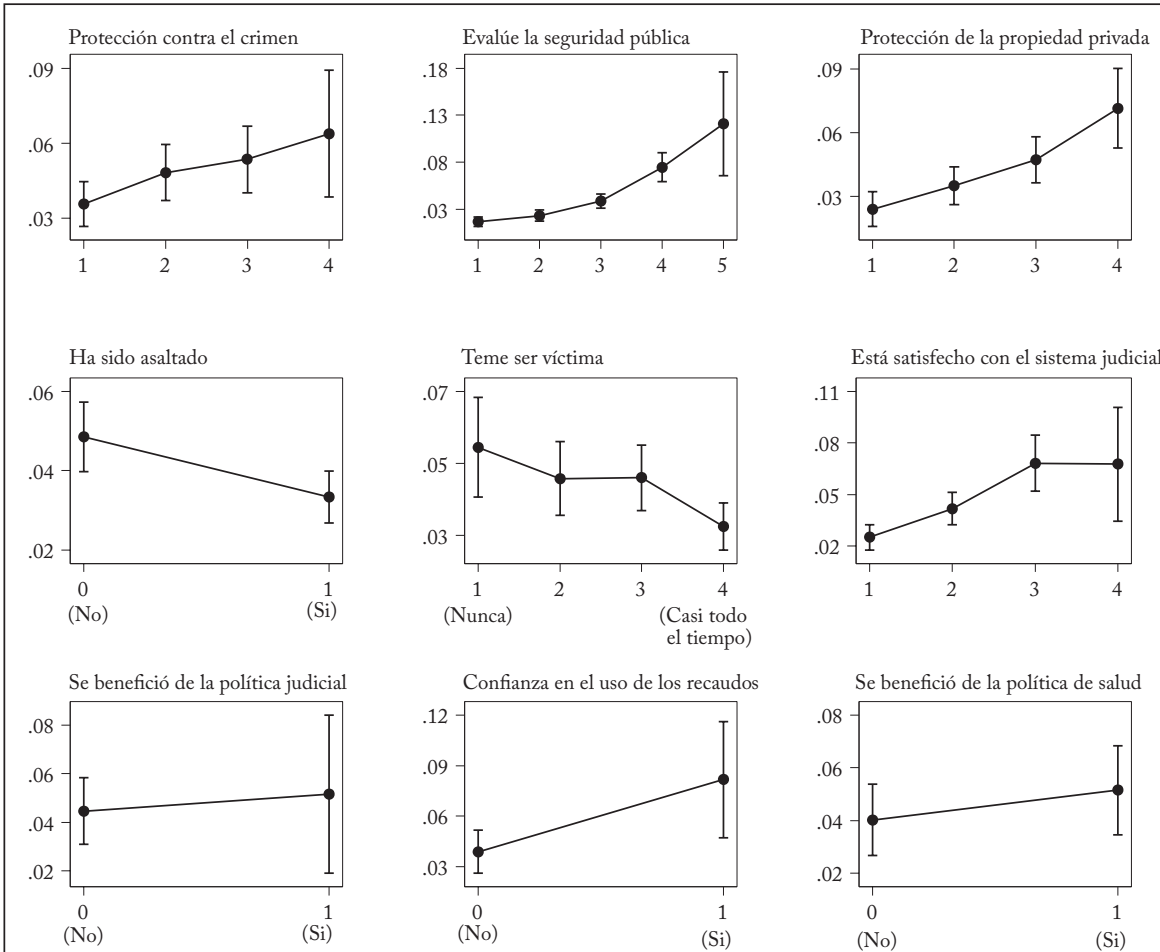

Se benefició de la política educativa

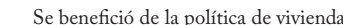

Lo que ha hecho el Estado por usted
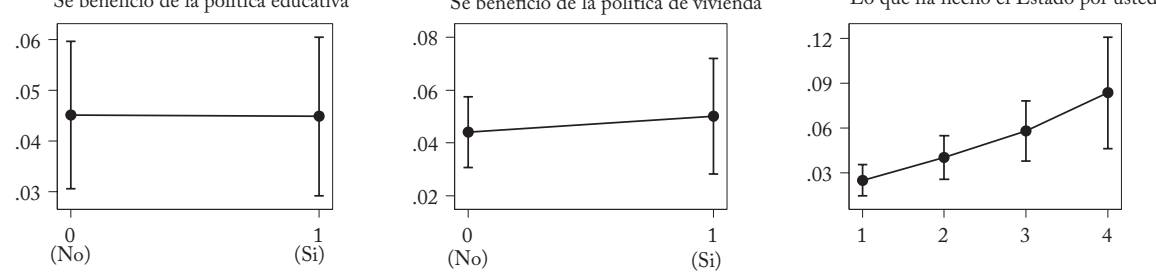

* Si en el anexo no se especifica lo contrario, un mayor valor en el eje x corresponden a una mayor valoración. Nivel de confianza $=95 \%$.

negativa y no significativa con ha sido asaltado y ninguna con teme ser una víctima. Se encontraron relaciones positivas y significativas con ambas variables de administración de justicia, así como con confianza en el uso de los recaudos y cuánta gente paga impuestos (no se ilustran en las gráficas; ver el cuadro 1). Y, como en los casos anteriores hay una relación positiva y significativa con lo que ha hecho el Estado por usted. Con las políticas de salud y de vivienda hay una relación positiva pero no significativa. 
Gráfica 2c

La democracia ha mejorado

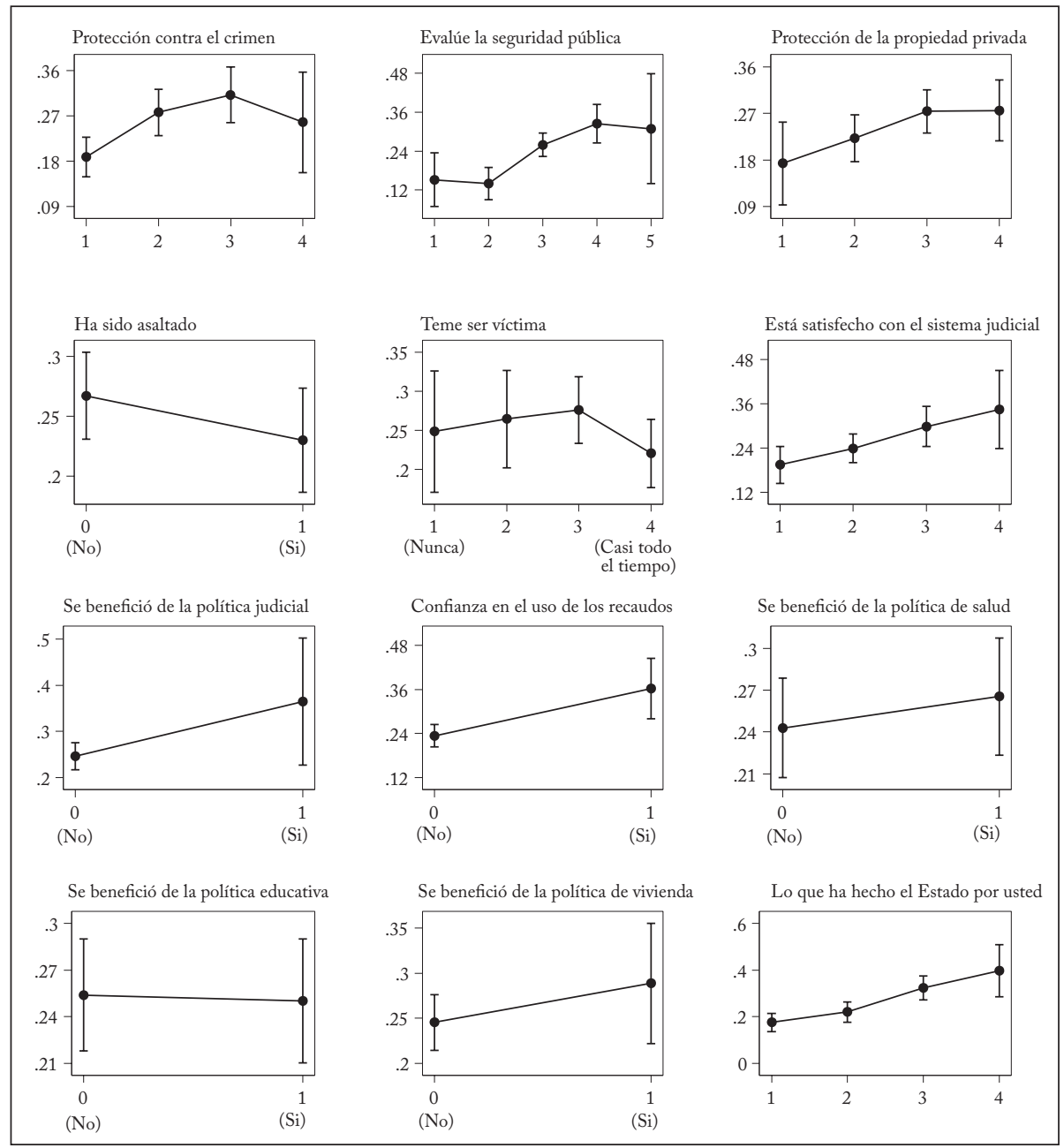

* Si en el anexo no se especifica lo contrario, un mayor valor en el eje x corresponden a una mayor valoración. Nivel de confianza $=95 \%$.

Las percepciones de protección contra el crimen, de protección de la propiedad privada y la evaluación de la seguridad pública siempre están relacionadas estadísticamente, en la dirección esperada, con el apoyo a los principios y el desempeño de la democracia. Otras variables consistentes con las tres variables dependientes son está satisfecho con el sistema judicial y lo que ha hecho el Estado por usted.

Haberse beneficiado de la política educativa y el temor a ser víctima tienen una ligera asociación con los principios democráticos, pero 
no con el desempeño democrático. En cambio, haber sido asaltado y confianza en el recaudo tributario están asociados con el desempeño democrático, pero no con los principios democráticos.

Algunos ejemplos ayudan a ilustrar la relación entre la evaluación de la capacidad del Estado y el apoyo a la democracia. Manteniendo todo lo demás en su valor medio, una persona que considera que no hay ninguna protección contra el crimen tiene una probabilidad del 14,7\% de responder que está totalmente de acuerdo con que la democracia es el mejor sistema de gobierno. Para una persona que siente que la protección contra el crimen está plenamente garantizada, la probabilidad se eleva al 20,5\%. Igualmente, una persona que califica "muy buena" a la seguridad pública tiene una probabilidad del $11,6 \%$ de responder que está satisfecha con el funcionamiento de la democracia, mientras que para alguien que la califica "muy mala", la probabilidad se reduce al $1,6 \%$. Por último, una persona que confía en la manera de usar los impuestos tiene una probabilidad del 36\% de contestar que cree que la democracia ha mejorado; para quien no tiene esa confianza, la probabilidad es de solo el $23 \%$.

Se estimaron dos conjuntos de especificaciones para probar la robustez. En primer lugar, para los modelos anteriores (estimados con regresiones logit ordinales) se emplearon regresiones probit ordinales y mínimos cuadrados ordinarios. El segundo conjunto incluye múltiples variables de estado - una para cada dimensión- en el lado derecho de la ecuación de la regresión logit ordinal, para cada variable de democracia. Los resultados de ambos conjuntos fueron muy parecidos a los que se acaban de discutir.

\section{ESTADO, DEMOCRACIA Y CONSTRUCCIÓN DE PAZ}

La sección anterior presentó evidencia que indica que las evaluaciones desfavorables de la capacidad estatal se asocian a bajos niveles de apoyo a los principios democráticos y a una evaluación menos positiva del desempeño de la democracia. En especial, las percepciones sobre seguridad personal, administración de justicia y confianza en el recaudo tributario están asociadas a medidas de apoyo a la democracia.

Esta evidencia contribuye a la discusión sobre si el apoyo al régimen es estable y no se ve afectado por su desempeño. La evidencia coincide con la de otros autores en que las experiencias con respecto a la efectividad del gobierno y a la calidad de la formulación y ejecución de políticas sí afectan las preferencias acerca del régimen y las tasas de aprobación. El apoyo a los principios democráticos depende no 
solo del conocimiento de las personas acerca de ellos, sino también de sus experiencias con el funcionamiento de la democracia.

La relación entre capacidad del Estado y democracia es particularmente importante en un escenario de postconflicto, dado el énfasis en la adopción de mecanismos democráticos como una salida de la confrontación armada; pues en el contexto de Estados débiles ha tenido consecuencias desastrosas. Siguiendo las ideas de Huntington (1968) sobre desarrollo político, y aplicándolas a la experiencia postconflicto de Ruanda y Bosnia, algunos estudiosos han llamado la atención sobre la importancia de fortalecer las instituciones estatales y adoptar políticas que limiten los conflictos sociales antes de liberalizar sus sistemas económicos y políticos (Barnett, 2006; Paris, 2004)².

Como ya se dijo, los acuerdos de La Habana entre el gobierno y las Farc incluyen disposiciones encaminadas a fortalecer instituciones estatales y a propiciar la apertura democrática. De hecho, el concepto de "paz territorial", que subyace en el proceso de construcción de paz en Colombia, considera que la democracia es el mejor mecanismo para consolidar la paz, y contempla la movilización de la población en procesos participativos de planeación desde abajo. Reconoce la importancia de fortalecer las instituciones estatales con el fin de garantizar los derechos ciudadanos de manera justa y equitativa. Promueve la inclusión y la participación como base de los procesos de transformación regional y fortalecimiento institucional (Jaramillo, 2014).

En este artículo se ha estudiado la relación entre capacidad estatal y apoyo a la democracia, que plantea al menos dos posibilidades -un reto y una oportunidad-para un país que aspira a la apertura de sus espacios democráticos para incorporar nuevos actores políticos y propiciar la movilización ciudadana. Por un lado, y pese a los avances logrados por el Estado colombiano en los últimos años, puede haber preocupaciones por las reducidas capacidades estatales, que podrían reducir la posibilidad de una apertura democrática exitosa. Es decir, si el Estado colombiano en el postconflicto no cumple las crecientes expectativas de sus ciudadanos, habrá pocas probabilidades de lograr este objetivo de los acuerdos de La Habana (Felbab-Brown, 2016). Por el otro, la apertura de espacios democráticos, junto con los ajustes institucionales requeridos para mejorar la capacidad del Estado, podría llevar a mejores valoraciones de dicha capacidad y a crear un círculo virtuoso entre apertura democrática y fortalecimiento del Estado.

2 También hay evidencia del papel de la capacidad estatal para garantizar la implementación de los acuerdos de paz (De Rouen, Ferguson et al., 2010). 
El artículo muestra que, en Colombia, los problemas asociados a la presencia de organizaciones criminales y otros actores que afectan la seguridad pública, la debilidad del poder judicial y la insuficiente capacidad del Estado para garantizar los derechos ciudadanos están asociados a un menor apoyo a la democracia. En un escenario de postconflicto, esta situación es más compleja y podría traducirse en escepticismo hacia los mecanismos y prácticas democráticas que se deberían poner en marcha para llevar a cabo la construcción de la paz.

Estos problemas serán más severos en regiones marginales de escasa población, donde el Estado es más débil y la acumulación del capital es más lenta y habrá menos incentivos para emprender acciones decisivas orientadas a transformar tales territorios (Duncan, 2014). En esas regiones, la dependencia económica de actividades ilegales como la minería ilegal y el narcotráfico puede impedir que los actores estatales cumplan sus obligaciones, o llevar a que sean cooptados; prueba de ello son las dificultades de seguridad que enfrentan regiones como el Catatumbo y el departamento de Nariño luego de la firma del acuerdo con las Farc. Si el Estado no satisface las demandas de los ciudadanos, especialmente en esas regiones, el apoyo a la democracia y a sus mecanismos se deteriorará, y quedará pendiente un componente importante de los acuerdos de La Habana. Esta situación resalta la importancia de que el Estado cumpla esos acuerdos en las regiones más afectadas por el conflicto.

Antes de llegar a conclusiones definitivas, cabe destacar que los resultados de la sección empírica no establecen una relación causal de la capacidad estatal al apoyo democrático, y que en realidad hay espacio para una relación causal inversa. Es decir, también son compatibles con una situación en la que cambios en el apoyo a la democracia llevan a cambios en la valoración de la capacidad estatal. De ser así, abrir espacios de deliberación democrática en la etapa de construcción de paz, siempre que sean percibidos como innovaciones democráticas, podría mejorar la valoración de la capacidad estatal.

Aunque no ocurrieron en situación de postconflicto, así sucedió en el caso de iniciativas como la campaña por la planeación descentralizada en Kerala, India, y el proceso de presupuestos participativos en Porto Alegre, Brasil. En ambos escenarios, la democratización avanzó de la mano con el desarrollo de la capacidad de los actores locales y se tradujo en mejor prestación de servicios, desarrollo económico e inclusión social (Baiocchi, Heller y Silva, 2011; Heller, Harilal y Chaudhuri, 2007). 
Los espacios creados por los acuerdos de La Habana para discutir temas como el desarrollo rural y la sustitución de cultivos ilegales, así como los incentivos a los presupuestos participativos y a la planeación local, tienen potencial para generar dinámicas locales que permitan abordar las tensiones entre capacidad local del Estado y democratización. En ese escenario, la experiencia internacional muestra el papel esencial de la sociedad civil y de los movimientos sociales para garantizar procesos sostenibles, y la importancia de un Estado central fuerte y de un proyecto político bien definido (Heller, 2011). En el caso colombiano, si se considera la etapa de construcción de paz como una oportunidad para construir Estado, es necesario convertir la iniciativa de construcción de paz en dicho proyecto político.

Por tanto, al menos en el corto plazo, la movilización exitosa de la ciudadanía hacia actividades de construcción de paz podría traducirse en una mejor valoración de las instituciones estatales y podría contribuir al círculo virtuoso entre apertura democrática y capacidad estatal. Sin embargo, en el mediano y el largo plazo, el fracaso del Estado para cumplir las expectativas de la población aumentaría el déficit democrático y la insatisfacción con la democracia. En ese contexto alternativo, el fracaso para corregir problemas del sistema político como el clientelismo masivo y la presencia de intereses ilegales en dicho sistema no solo afectaría la legitimidad de la representación y la participación, sino que se traduciría en peores evaluaciones de la capacidad estatal. Como ya se mencionó, siempre hay grandes peligros asociados a un Estado débil en escenarios de postconflicto.

Movilizar a la ciudadanía, como proponen los acuerdos de La Habana, sin hacer reformas que cambien la percepción ciudadana de la eficiencia de las instituciones puede degenerar en que un mayor número de ciudadanos cívicamente activos recurran a formas radicales de participación política como las protestas masivas (Moseley, 2015).

A manera de cierre, cabe decir que el plebiscito de 2016 exacerbó las posiciones políticas en torno al acuerdo de paz, y que estas se han radicalizado con motivo de los programas para implementarlo. Sin embargo, la combinación de esfuerzos para fortalecer la presencia del Estado en el territorio y las oportunidades que el acuerdo brinda para profundizar la democracia pueden generar un círculo virtuoso que conduzca a un escenario de postconflicto exitoso. 


\section{CONCLUSIONES}

El contexto global de retroceso de la democracia plantea retos fuertes a los países que buscan profundizarla. Esto es especialmente cierto en Colombia, donde el proceso hace parte de un acuerdo de paz con un grupo armado ilegal que busca poner fin a un enfrentamiento violento de más de cincuenta años.

La evidencia empírica que presenta este artículo muestra que la insatisfacción de los ciudadanos con los principios y el desempeño de la democracia en Colombia está fuertemente asociada a la deficiente capacidad del Estado para cumplirles en materia de seguridad, administración de justicia, recaudo de impuestos y garantía de derechos.

Esto se podría traducir en un obstáculo importante para cambiar las condiciones básicas en las zonas más afectadas por el conflicto armado. Sin embargo, si se aprovecha la posibilidad de una causalidad inversa, de apoyo a la democracia a valoración de la capacidad estatal, la apertura de espacios de deliberación democrática, en desarrollo de los acuerdos de La Habana, puede facilitar la consolidación del Estado en todo el territorio. Si el impulso inicial asociado a esta innovación democrática se tradujera en el fortalecimiento del Estado en las zonas afectadas, el fin del conflicto con las Farc abriría la posibilidad de generar el círculo virtuoso de apertura democrática y fortalecimiento del Estado que se requiere para el desarrollo político.

\section{ANEXO}

\section{DESCRIPCIÓN DE LAS VARIABLES}

Preguntas del Latinobarómetro incluidas en el análisis.

a. Las variables dependientes se basaron en las siguientes preguntas:

1. (La democracia es el mejor sistema) ¿Está totalmente de acuerdo, de acuerdo, en desacuerdo o totalmente en desacuerdo con la afirmación: la democracia puede tener problemas, pero es el mejor sistema de gobierno? Las respuestas se codificaron en una escala de 4 puntos, donde: 4 = totalmente de acuerdo, $3=$ de acuerdo, 2 = en desacuerdo y 1 = totalmente en desacuerdo (incluida en los conjuntos de datos de 2011, 2013 y 2015).

2. (Satisfacción con la democracia) ¿Está muy satisfecho, más bien satisfecho, no muy satisfecho o nada satisfecho con el funcionamiento de la democracia en Colombia? Las respuestas a esta pregunta se codificaron en una escala de 4 puntos, donde 4 = muy satisfecho, 3 = más bien satisfecho, 2 = no muy satisfecho, 1 = nada satisfecho (incluida en los conjuntos de datos de 2011, 2013 y 2015).

3. (La democracia ha mejorado) ¿Cree que la democracia en Colombia ha mejorado, se ha mantenido igual o ha empeorado? Las respuestas a esta pregunta se codi- 
ficaron en una escala de 3 puntos, donde 3 = ha mejorado, 2 = se ha mantenido igual y 1 = ha empeorado (incluida únicamente en el conjunto de datos de 2011).

b. Las variables independientes se basaron en las siguientes preguntas:

Las respuestas a las dos preguntas siguientes usan los siguientes criterios: Totalmente garantizada -4 , algo garantizada -3 , poco garantizada -2 , para nada garantizada - 1:

4. (Protección contra el crimen) ¿Hasta qué punto está garantizada la protección contra el crimen en Colombia? (incluida en los conjuntos de datos de 2011 y 2015).

5. (Protección de la propiedad privada) ¿Hasta qué punto está garantizada la protección de la propiedad privada en Colombia? (incluida en los conjuntos de datos de 2011 y 2015).

Las respuestas a las cuatro preguntas siguientes usan los siguientes criterios: No mencionado $=0$. Mencionado $=1$.

¿Cuáles de las siguientes políticas públicas lo han beneficiado a usted y a su familia?:

6. (Beneficiado de la política de salud) Política de salud (incluida únicamente en el conjunto de datos de 2011).

7. (Beneficiado de la política educativa) Política educativa (incluida únicamente en el conjunto de datos de 2011).

8. (Beneficiado de la política de vivienda) Política de vivienda (incluido únicamente en el conjunto de datos de 2011).

9. (Beneficiado de la política judicial) Política judicial (incluida únicamente en el conjunto de datos de 2011).

Las respuestas a las dos preguntas siguientes usan los siguientes criterios: No mencionado $=0$. Mencionado $=1$.

10. (Ha sido asaltado) ¿Usted o algún pariente ha sido asaltado, agredido o víctimas de un delito en los últimos 12 meses? (incluida en los conjuntos de datos de 2011, 2013 y 2015).

11. (Confianza en el uso de los impuestos) En general, ¿confía en que el dinero de los impuestos será bien gastado por el Estado? (incluida únicamente en el conjunto de datos de 2011).

12. (Satisfacción con el sistema judicial) ¿Diría usted que está muy satisfecho (4), más bien satisfecho (3), no muy satisfecho (2) o nada satisfecho (1) con el funcionamiento del sistema judicial en Colombia? (incluido únicamente en el conjunto de datos de 2011).

13. (¿Cuántas personas pagan impuestos?) Por lo que usted sabe o ha oído, en una escala de 1 a 100, donde 1 es "ninguno" y 100 es “todos”, ¿cuántos colombianos que teniendo que pagar impuestos los pagan debidamente? (incluida únicamente en el conjunto de datos de 2011).

14. (Califique la seguridad ciudadana) ¿Cómo calificaría la seguridad ciudadana en Colombia? Las respuestas a esta pregunta tenían una escala de 5 puntos y se recodificaron de 5 (muy buena) a 1 (muy mala) (incluida en los conjuntos de datos de 2011, 2013 y 2015).

15. (Preocupación por ser víctima) ¿Cuán frecuentemente se preocupa usted de que pueda ser víctima de un delito con violencia? Las respuestas se codificaron en una escala de 4 puntos, donde 4 = todo o casi todo el tiempo, $3=$ algunas veces, 
2 ocasionalmente y 1 = nunca (incluida únicamente en el conjunto de datos de 2011).

16. (Lo que el Estado ha hecho por usted) ¿Cuánto ha hecho el Estado por usted y su familia en los últimos tres años? Las respuestas se codificaron en una escala de 4 puntos, donde 4 = mucho, $3=$ algo, 2 = poco y 1 = nada (incluida únicamente en el conjunto de datos de 2011).

Las variables de control se basaron en las siguientes preguntas (incluidas en todos los conjuntos de datos:

17. $($ Sexo $)$ Sexo del entrevistado: $1=$ masculino, $0=$ mujer

18. (Edad) ¿Cuál es su edad?

19. (Nivel de educación) ¿Qué estudios ha realizado? ¿Cuál es el último año cursado? ¿En qué tipo de establecimiento cursó sui educación secundaria?

20. (Nivel de ingresos) El salario o sueldo que recibe y el total del ingreso familiar ¿iles permite cubrir satisfactoriamente sus necesidades? ¿En cuál de estas situaciones se encuentra usted? Las respuestas se codificaron en una escala de 4 puntos, donde 4 = les alcanza bien, pueden ahorrar, $3=$ les alcanza justo, sin grandes dificultades, 2 = no les alcanza, tienen dificultades, 1 = no les alcanza, tienen grandes dificultades.

21. (Ideología) En política, las personas se habla normalmente de "izquierda" y "derecha". En una escala donde 0 es "izquierda” y 10 es "derecha", ¿dónde se ubicaría usted?

22. (Religiosidad) Si tiene una religión, ¿cómo se considera? Las respuestas se codificaron en una escala de 4 puntos, donde $4=$ muy practicante, $3=$ practicante, $2=$ no muy practicante, $y 1=$ no practicante.

\section{ESTADÍSTICAS DESCRIPTIVAS}

\begin{tabular}{|c|c|c|c|c|c|}
\hline Variables & Número & Media & $\begin{array}{c}\text { Desviación } \\
\text { estándar }\end{array}$ & Mínimo & Máximo \\
\hline Democracia como mejor sistema & 3.451 & 2,9331 & 0,6961 & 1 & 4 \\
\hline Satisfacción con la democracia & 3.481 & 2,1138 & 0,7707 & 1 & 4 \\
\hline Democracia ha mejorado & 1.172 & 1,9770 & 0,7076 & 1 & 3 \\
\hline Protección contra el crimen & 2.380 & 1,9748 & 0,9092 & 1 & 4 \\
\hline Evalúe la seguridad pública & 3.591 & 2,8635 & 0,8808 & 1 & 5 \\
\hline Protección de la propiedad privada & 2.358 & 2,6115 & 0,9073 & 1 & 4 \\
\hline Ha sido asaltado & 3.588 & 0,4033 & 0,4906 & 0 & 1 \\
\hline Teme ser víctima & 3.594 & 2,8904 & 1,0323 & 1 & 4 \\
\hline Está satisfecho con el sistema judicial & 2.318 & 2,1290 & 0,8164 & 1 & 4 \\
\hline Se benefició de la política judicial & 1.200 & 0,0450 & 0,2074 & 0 & 1 \\
\hline Confianza en el uso de los recaudos & 1.142 & 0,1427 & 0,3500 & 0 & 1 \\
\hline Cuánta gente paga impuestos & 1.155 & 55,8719 & 23,187 & 1 & 100 \\
\hline Se benefició de la política de salud & 1.200 & 0,4142 & 0,4928 & 0 & 1 \\
\hline Se benefició de la política educativa & 1.200 & 0,3300 & 0,4704 & 0 & 1 \\
\hline Se benefició de la política de vivienda & 1.200 & 0,1525 & 0,3597 & 0 & 1 \\
\hline Lo que ha hecho el Estado por usted & 1.199 & 2,1226 & 0,9733 & 1 & 4 \\
\hline Género (masculino =1) & 3.600 & 0,4764 & 0,4995 & 0 & 1 \\
\hline Edad & 3.600 & 40,403 & 16,139 & 18 & 94 \\
\hline Nivel de educación & 3.600 & 12,493 & 3,8940 & 1 & 17 \\
\hline Nivel de ingreso & 3.574 & 2,4077 & 0,8479 & 1 & 4 \\
\hline Ideología & 2.984 & 5,9186 & 2,5691 & 0 & 10 \\
\hline Religiosidad & 3.327 & 2,6546 & 0,8052 & 1 & 4 \\
\hline
\end{tabular}




\section{REFERENCIAS BIBLIOGRÁFICAS}

Alviar, H., Azuero, A. y Bejarano, A. (2009). La dimensión constitucional de la democracia, Documentos de Trabajo 7, Bogotá: PNUD, IDEA Internacional.

Andersen, D., Møller, J., Rørbæk, L. L. et al. (2014). State capacity and political regime stability. Democratization, 21(7), 1305-1325.

Armingeon, K. y Guthmann, K. (2014). Democracy in crisis? The declining support for national democracy in European countries, 2007-2011. European Journal of Political Research, 53(3), 423-442.

Baiocchi, G., Heller, P. y Silva, M. (2011). Bootstrapping democracy: Transforming local governance and civil society in Brazil. Stanford: Stanford University Press.

Barnett, M. (2006). Building a republican peace: Stabilizing states after war. International Security, 30(4), 87-112.

Berman, S. (2007). Lessons from Europe. Journal of Democracy, 18(1), 28-41.

Bratton, M. y Mattes, R. (2001). Support for democracy in Africa: Intrinsic or instrumental? British Journal of Political Science, 31(3), 447-474.

Carothers, T. (2007). The "sequencing" fallacy. Journal of Democracy, 18(1), 12-27.

Centeno, M. A. (2002). Blood and debt: War and the Nation-State in Latin America. Harrisburg: Penn State University Press.

CNMH. (2013). Guerrilla y población civil. Trayectoria de las FARC 19492013. Bogotá: Centro Nacional de Memoria Histórica.

Cooley, A. (2015). Countering democratic norms. Journal of Democracy, 26(3), 49-63.

Danahar, P. (2013). The new Middle East: The world after the Arab spring. Londres: Blomsbury Press.

De La Calle, H. (2008). Reforma electoral en Colombia. En D. Zovatto y J. Orozco (eds.), Reforma politica y electoral en América Latina: 1978 2007 (pp. 391-456). México: UNAM/Idea Internacional.

Delegación del Gobierno Nacional y Delegación de las FARC-EP. (2013). Participación politica: apertura democrática para construir la paz. La Habana: República de Colombia.

DeRouen, K., Ferguson, M. J. et al. (2010). Civil war peace agreement implementation and state capacity. Journal of Peace Research, 47(3), 333-346.

Diamond, L. (2009). The spirit of democracy: The struggle to build free societies throughout the world. Nueva York: St. Martin's Griffin.

Diamond, L. (2015). Facing up to the democratic recession. Journal of Democracy, 26(1), 141-155.

Diamond, L. (2016). Democracy in decline how Washington can reverse the tide. Foreign Affairs, julio-agosto.

DNP. (2011a). Bases del Plan Nacional de Desarrollo, 2010-2014. Bogotá: DNP.

DNP. (2011b). Plan Nacional de Desarrollo, 2010-2014. Prosperidad para todos. Bogotá: DNP.

Duncan, G. (2014). Más que plata o plomo. El poder politico del narcotráfico en Colombia y México. Bogotá: Debate. 
Easton, D. (1965). A systems analysis of political life. Nueva York: Wiley. Felbab-B., V. (2016). ¿Quién paga por la paz en Colombia? Revista de Economía Institucional 18(35), 13-38.

Fernandez, K. y Kuenzi, M. (2010). Crime and support for democracy in Africa and Latin America. Political Studies, 58(3), 450-471.

Fukuyama, F. (2014). Political order and political decay: From the industrial revolution to the globalization of democracy. Nueva York: Farrar, Straus and Giroux.

Fukuyama, F. (2015). Why is democracy performing so poorly? Journal of Democracy, 26(1), 11-20.

Garay, L. J. y Salcedo-A., E. (2012). Narcotráfico, corrupción y Estados. Cómo las redes ilicitas han reconfigurado las instituciones en Colombia, Guatemala y México. Debate.

García, M. (2008). Jueces sin Estado. La justicia colombiana en zonas de conflicto armado. Bogotá: Siglo del Hombre Editores. DeJusticia. Konrad Adenauer Stiftung. The John Merck Fund.

Gómez, F. (2009). La restitución de la tierra y la prevención del desplazamiento forzado en Colombia. En C. Charruca y Mertens (eds.). Desplazamiento en Colombia. Prevenir, asistir, transformar. Cooperación internacional e iniciativas locales (pp. 131-180). Bogotá: La Carreta Social.

González, F. (2014). Poder y violencia en Colombia. Bogotá: ODECOFI.

González, F., Bolívar, I. y Vásquez, T. (2002). Violencia política en Colombia. Bogotá: CINEP.

Gutiérrez, F. (2014). El orangután con sacoleva. Cien años de democracia y represión en Colombia (1910-2010). Bogotá: IEPRI-Debate.

Gyimah-B., E. (2015). Africa's waning democratic commitment. Journal of Democracy, 26(1), 101-113.

Haerpfer, C. W. (2008). Support for democracy and autocracy in Russia and the commonwealth of independent States, 1992-2002. International Political Science Review, 29(4), 411-431.

Heller, P. (2001). Moving the state: The politics of democratic decentralization in Kerala, South Africa, and Porto Alegre. Politics E Society, 29(1), 131-163.

Heller, P., Harilal, K. N. y Chaudhuri, S. (2007). Building local democracy: Evaluating the impact of decentralization in Kerala, India. World Development, 35(4), 626-648.

Huntington, S. P. (1968). Political order in changing societies. Estados Unidos: Yale University Press.

Inglehart, R. (1997). Modernization and postmodernization. Princenton: Princeton University Press.

Inglehart, R. (1999). Postmodernization erodes respect for authority, but increases support for democracy. En P. Norris (ed.), Critical citizens. Global support for democratic governance (pp. 236-256). Oxford: Oxford University Press.

Inglehart, R. y Welzel, C. (2005). Modernization, cultural change, and democracy: The buman development sequence. Cambridge: Cambridge University Press. 
Inglehart, R. y Welzel, C. (2010). Changing mass priorities: The link between modernization and femocracy. Perspectives on Politics, 8(2), 551-567.

Jaramillo, S. (2014). Territorial peace. Cambridge, Mass: Harvard University.

Kalmanovitz, S. (2010). Nueva historia económica de Colombia. Bogotá: Taurus.

Kotzian, P. (2011). Public support for liberal democracy. International Political Science Review, 32(1), 23-41.

Krieckhaus, J. et al. (2014). Economic inequality and democratic support. Journal of Politics, 76(1), 139-151.

Levitsky, S. y Way, L. A. (2010). Competitive authoritarianism. Hybrid regimes after the cold war. Cambridge: Cambridge University Press.

Magalhães, P. C. (2014). Government effectiveness and support for democracy. European Journal of Political Research, 53(1), 77-97.

Mainwaring, S. y Pérez-L., A. (2015). Cross-currents in Latin America. Journal of Democracy, 26(1), 114-127.

Mansfield, E. y Snyder, J. (2007). The sequencing "fallacy". Journal of Democracy, 18(3), 5-10.

Masoud, T. (2015). Has the door closed on Arab democracy? Journal of Democracy, 26(1), 74-87.

Micklethwait, J. y Wooldridge, A. (2014). The fourth revolution: The global race to reinvent the State. Nueva York: Penguin Press.

Mill, J. S. (1862). Considerations on representative government. Londres: Public Domain Books.

Møller, J. y Skaaning, S. E. (2013). The third way: Inside the numbers. Journal of Democracy, 24(4), 97-109.

Moseley, M. W. (2015). Contentious engagement: Understanding protest participation in Latin American democracies. Journal of Politics in Latin America, 7(3), 3-48.

Norris, P. (1999). Introduction: The growth of critical citizens? En P. Norris (ed.), Critical citizens. Global support for democratic governance (pp. 1-13). Oxford: Oxford University Press.

Norris, P. (2011). Democratic deficit. Critical citizens revisited. Cambridge: Cambridge University Press.

Paris, R. (2004). At war's end: Building peace after civil conflict. Cambridge, Mass: Cambridge University Press.

Paris, R. (2006). Bringing the leviathan back in: Classical versus contemporary studies of the liberal peace. International Studies Review, $8(3), 425-440$.

Patiño, C. A. (2012). Guerra y construcción del Estado en Colombia 1810 2010. Bogotá: Universidad Militar Nueva Granada.

PNUD. (2011). Colombia rural. Razones para la esperanza. Informe nacional de desarrollo bumano 2011. Bogotá.

Rudra, N. (2005). Globalization and the strengthening of democracy in the developing world. American Journal of Political Science, 49(4), 704-730.

Rupnik, J. (2012). How things went wrong? Journal of Democracy, 23(3), 132-137. 
Shevtsova, L. (2015). Forward to the past in Russia. Journal of Democracy, 26(2), 22-36.

Velásquez, F. (2015). Participación ciudadana en el proceso de paz de El Caguán. Bogotá.

Velásquez, F. y González, E. (2003). ¿Qué ha pasado con la participación ciudadana en Colombia? Bogotá: Fundación Corona.

Warren, M. (2006). Democracy and the State. En J. Dryzek et al. (eds.), Handbook of political theory (pp. 382-399). Oxford, Nueva York: Oxford University Press. 